\title{
An Investigation of Early Socialization and Socio-Interactions in Higher Teacher Education Institutions
}

\author{
Abdul Razaq Ahmad1, Najamuddin Bachora1, Mohd Mahzan Awang1, Suarman² \\ ${ }^{1}$ Faculty of Education, National University of Malaysia \\ ${ }^{2}$ Faculty of Education, University of Riau, Indonesia \\ Email: razaq@ukm.edu.my
}

Received 25 November 2015; accepted 26 January 2016; published 29 January 2016

Copyright (C) 2016 by authors and Scientific Research Publishing Inc.

This work is licensed under the Creative Commons Attribution International License (CC BY).

http://creativecommons.org/licenses/by/4.0/

(c) (i) Open Access

\section{Abstract}

This study investigated the influence of early socialization of pre-service teachers and their tendency for interactions towards racial unity in Malaysian higher teacher education institutions. Early socialization in this study refers to the influences of family, school, peers and the mass media. Meanwhile, the interaction aspects refer to the tendency for interaction in different institutional environments among multi-ethnic pre-service teachers during their involvement in curricular activities, co-curricular activities, campus environment and daily in-campus activities. The unity in this study focuses on the appreciation of the values for unity and how it affects the tendency for interaction with multi-ethnic pre-service teachers. The current study utilized a survey research design where a number of 299 pre-service teachers from Higher Teacher Education Institutions (TEI) in the East Malaysia were randomly selected. A set of adapted questionnaires were used as the instruments. The pilot test using Cronbach alpha analysis showed all the items of the constructs are at a high value level between 0.775 and 0.957 . This informs that the instruments are valid and reliable to be used. Descriptive statistics involved means and percentages whereas inferential statistics used a structural equation model (SEM). The mean score of the tendency for interaction and unity among multi-ethnic pre-service teachers is between 4.17 and 4.7. Meanwhile, the mean scores for unity appreciation aspects among multi-ethics are also at a higher level with the mean scores between 4.19 and 4.41. This indicates that there is a higher level of interaction for unity as well as unity appreciation. Structural Equation Modeling (SEM) analysis showed the following subconstructs i.e. family, school and peer pressure are significantly contributed to the tendency of interaction and appreciation towards the values for unity among multi-ethnic pre-service teachers, where the coefficients paths are 8.712, beta 0.504 (family variable); 5.441 , beta 0.288 (school milieu variable); and 3.407, beta 0.183 (peer pressure variable) respectively. These data suggest that those three factors mentioned are supposed to be taken into account in designing and implementing activities for unity in multi-ethnic higher teacher education community. 


\section{Keywords}

\section{Interaction, Diversity, Cohesion, Unity, Teachers, Structural Equation Modeling (SEM)}

\section{Introduction}

This study aims at identifying the influence of early socialization of pre-service teachers on the tendency for social interaction among multi-ethnic teachers in higher teacher education institutions in East Malaysia. In order to get better understanding on contextual aspects of the current study, a brief introduction on socio-historical context of Malaysia is essential. The country gained its independence in 1957 and the consolidation of the Malay Peninsula, Sabah and Sarawak into the Federation in 1963 to form Malaysia. However, there are always questions on racial integration and unity as Malaysia is not a homogeneous country but a plural society. Due to that, the Government has taken numerous attempts to integrate the people through political, economic and social development approaches in order to reduce the features of plurality and to prevent conflicts if they are not addressed smartly. Due to that, the education system is one of the most important and effective tool for setting up national identity, nationalism and fostering love for the country and national unity (Baharuddin, 2007). Education is also considered as a way to reduce ethnic and racial differences. This is because the system has a platform to provide knowledge about the various cultures existing in the society. Hence, understanding this matter will result in open acceptance regarding the existence of social diversity and tolerance for all forms of social order. Education system should be beyond races and is the site to firm, nurture and grow the values of tolerance, friendliness, cooperation, understanding and inculcating values that uphold unity (Ramli, 2009).

\section{Literature Review}

\section{Interaction and Early Socialization}

It is undeniable that interaction is the key and foundation of human life. In fact, human interaction is also the main social activity as people are in dire need of interaction with others in every single activity of their lives. By interacting with others, people are able to express all their needs and requirements. Particularly, humans are social animals who do not like to live in isolation without immediate friends in the neighborhood. Therefore, as students, interaction with others in the learning environment is needed, including with those of different ethnic groups.

Social interaction between individuals of different ethnic groups will only happen if the individuals are being in the same setting of a multi-ethnics environment (Baharuddin, 2007). This is because, in such circumstances, students do not have any other way but to interact with other partners to continue living harmoniously in campus. In fact, with the present of conducive setting and infrastructure students will have broad opportunities to mix with others of various ethnic groups (Khairi, 2011). This will expedite the process of accepting differences found between them. In fact, campus interaction such as in classrooms, laboratories and other campus environment will provide a meaningful experience for the students' social development (Kim \& Sax, 2007).

Even so, the tendency for students to interact in a multi-ethnic environment is somehow influenced by their early socialization experienced prior or before they continue their lives in the institutes or campus. According to the Bronfenbrenner's (2005) ecological system theory, the main agents of early socialization are the family, school, peers and the mass media. These influential factors will have huge impact on students' interaction. This theory emphasizes on the influence of environment on individual development. In this context, the environment which encourages interaction among multi-ethnic pre-service teachers would influence the students' development and growth.

According to Dawi (2004, 2006), in the context of ethnic polarization among students, this likely to happen due to habitual actions that have been formed based on their different cultures. Dawi (2004) synthesised that the state of habit as it exists within individual as a result of a socialization process. Personal habits are also formed as a result of cultural acquisition in an area of life and will become a cultural asset and have the power to act as socialization agents. This cultural asset will influence social habits to act as personal trajectory. If the personal habit prior of entering university is a trajectory for unity, then it is likely the students will have a sense of unity with other people of different ethnic groups (Dawi, 2004).

In this case, early socialization experienced by children is very much associated with their interactions with 
the environment, and this will later influence their attitudes and behaviors in the future (Rodrigues-Garcia \& Wagner, 2009). Hence, Bronfenbrenner ecological theory is suitable to be used in studying the relationships of early socialization with pre-service teachers' tendency to interact with others in the institutes. The strength of this ecological theory is it emphasizes on various social environments which affect students' development, especially from the micro systems, such as family, school and peers (Dawi, 2006).

The education system is one of the most important and effective tool for setting up national identity, nationalism and fostering love for the country and national unity (Baharuddin, 2007). Education is also considered as a way to reduce ethnic and racial differences. This is because the education system has a platform to provide knowledge about the various cultures existing in the society (Seltzer \& Waterman, 1996). Hence, understanding this matter will result in open acceptance regarding the existence of social diversity and tolerance for all forms of social order. Past empirical research suggests that education system should be beyond races and is the site to firm, nurture and grow the values of tolerance, friendliness, cooperation, understanding and inculcating values that uphold unity. Relationship between individuals across ethnic boundaries is seen as a phenomenal social action that should be practiced by the whole nation.

In fact, in spite of successful economic development and relatively good relationship among people living in this unique plural society, there are still signs of problems in mutual understanding and getting consensus among people of different races and religions especially on nation building. The Community Tension Index had increased from 4.7 cases in 2011 to 4.9 cases in the third quarter of 2012 and the Global Harmony Index moved from rank 19 out of 153 countries in 2011 to the $20^{\text {th }}$ rank in the third quarter of 2012. Indeed, the younger generation began questioning the social contract which has been the core of unity and understanding between ethnics (Baharuddin, 2007). These young people began to question the special position of the Malays, the Malay language and the role of Islam as the official religion of the country and this could cause a prolonged conflict if not handled properly.

In addition, the education system is said to be an effective avenue for socialization and dissemination of cultural values (Tamam, 2009). However, it is still unclear how it can produce huge impacts particularly in encouraging tolerance, reducing prejudice and diminishing discrimination against any group. It is very difficult to realize unity through the education system if the system still provides basic education which emphasizes on certain values of the original ethnics (Chang, 1999). The vernacular schools system has to be blamed as a factor that magnifies the gap between ethnics, which indirectly weaken unity (Ahmad, Saleha, Jelas, \& Seman, 2010). This is because previous studies on ethnic relations in the context of education system had found problems in terms of ethnic interaction especially ethnic polarization (Dawi, 2004; Umbach \& Kuh, 2006).

Most students prefer to interact with someone who is the same ethnic group with them. It is said to be influenced by agents of early socialization particularly by parents and family members (Karim \& Meerah, 1986), by the schools (Zainal \& Mohamad, 2010), and also by the mass media (Peng, 2007). However, it is still uncertain on how early socialization agents influence students to interact with other multi-ethnic students in the institute, this is because there is yet any studies regarding this matter.

\section{Methodology}

This is a descriptive survey using questionnaires to gain insight about the pre-service teachers' tendency to interact with friends from various ethnic groups in the East of Malaysia (the states of Sabah and Sarawak). 74 items in the questionnaire were selected based on surveys of previous studies which consisted of questions on the tendency to interact in an environment (36 items) such as during curricular activities (8 items), co-curricular (7 items), residential colleges (7 items), daily activity (8 items) and websites (6 items). Secondly; the effects of early socialization (26 items) namely influences by family (8 items), school (7 items), peers (5 items) and mass media (6 items) and the third aspect is appreciation of the values for unity (12 items). All the items used 5 likerts scale from very not agree (1) to very agree (5). The samples were randomly selected. The stratified random group sampling was used to select only the third and eighth semester of preservice teachers. A total of 307 participants were chosen from the Institute of Teacher Education from the Sabah and Sarawak campuses. However, only 299 respondents were used for analysis, due to the existence of extreme data or outliers that needed to be removed so as not to affect the results of this study.

Based on Table 1, a pilot study was conducted to test the reliability of the constructs and the result was between 0.775 and 0.957 which showed higher scores of validity and reliability. Descriptive analysis using the mean scores was used to measure the level of tendency for interaction and the level of appreciation on the values 
for unity. The levels of tendency for interaction among multi-ethnic pre-service teachers are based according to Jamil (2002) and Aziz et al. (2009).

\section{Findings and Discussion}

\section{Demographic background}

Respondents were final year students from two education programs which have the highest number of registered students. They were the semester three pre-graduates of the Bachelor in Education Foundation Program and Semester eight pre-graduates of the Bachelor in Education. Table 2 shows the number of respondents from both programs. 59.5\% or 178 respondents were students from the Bachelor in Education Foundation Program in the third semester, whereas 121 students (40.5\%) were in the eighth semester.

Respondents were divided into several ethnic groups based on their religions, to best serve the purpose of this study. Based on the background research, the highest number of respondents was 184 (61.5\%), Muslims Malays and Bumiputra (Native people). The Malay Muslim students mostly from the west coast of Sabah were categorised together with some of the native people (the Bumiputra) who had converted as Muslims. The second highest number of respondents was 77 (25.8\%) non-muslim Bumiputra students, followed with 34 (12.7\%) students of the Chinese Ethnic. A total of 184 (61.5\%) was Muslims, whereas 30.8\% or 92 respondents were Christians and the remaining comprised of $7.7 \%$ or 23 respondents were Buddhists.

\subsection{Level of Tendency for Interaction and Appreciation of Unity among Multi-Ethnic Pre-Service Teachers}

Data showed that the overall mean level of tendency for interaction among multi-ethnic pre-service teachers was 4.32. This means that the tendency to interact is at a high level according to mean score interpretation (Jamil, 2002; Aziz et al. 2009). Results also suggest that there is a tendency for interaction among multi-ethnic pre-service teachers in all environments (high mean value of 4.17). The highest mean is for the tendency of multi-ethnic pre-service teachers interaction in the co-curricular environment with the mean value of 4.47, followed by the tendency of multi-ethnic pre-service teachers' interaction in the environment for daily activities (mean 4.35), interaction environment at the residential colleges (mean 4.30), and interaction at the curriculum setting. However, the lowest tendency of multi-ethnic pre-service teachers' interaction is via the websites. The findings of multi-ethnic pre-service teachers' interaction in the institutes are shown in Table 3.

This finding shows that the pre-service teachers do not have any problem to interact with their peers from different ethnic groups. Teachers are important agents of socialization when they are placed in schools in the future. Particularly this will help them to foster great interaction and unity among their future students. The results

Table 1. Interpretation of the mean score.

\begin{tabular}{cc} 
MIN SCORE & INTERPRETATION \\
\hline $1.00-2.33$ & Low \\
$2.34-3.66$ & Medium \\
$3.67-5.00$ & High \\
\hline
\end{tabular}

Table 2. Details information on the background of respondents.

\begin{tabular}{cccc}
\hline & Aspect & Number & Percentage \\
\hline Learning program & PPISMP Semester 3 & 178 & 59.5 \\
& PISMP Semester 8 & 121 & 40.5 \\
Ethnicity & Muslim Malays \& Bumiputera & 184 & 61.5 \\
& Non-muslim Bumiputera & 77 & 25.8 \\
Religion & Chinese & 38 & 12.7 \\
& Islam & 184 & 61.5 \\
& Christian & 92 & 30.8 \\
\hline
\end{tabular}


are consistent with results of previous studies that showed students who are living in campus with various kinds of people have a high level of interaction (Chang, 1999; Gurin et al., 2002).

However, there are also studies that indicated the level of students' interaction with various ethnic groups was at a moderate level and some even reported low. Among them were studies showed the level of interaction among students was at a moderate level. Whereas, a study by Ahmad, Saleha, Jelas, \& Seman (2010) on 335 students showed students' awareness and acceptance of school diversity was unsatisfactory and was at a low level. Similarly, a study by Mustapha, Azman, Karim, Ahmad, \& Lubis (2009) on the interaction climate of the university students found that the students were more likely to mix with other students who are coming from the same ethnic or racial group with them.

This situation must be addressed by the students' affair department. This is because of a solid consideration that interaction with people from different backgrounds and different life experiences will enhance one's knowledge and experience. Thus, the information can be used post-graduation especially they are living in a multi-cultural society (Umbach \& Kuh, 2006). In fact, cross-racial interaction will increase cognitive development, enhance self-academic and social capabilities (Chang, 1999; Gurin et al., 2002) improve civics (Chang, Astin, \& King, 2004) and provide meaningful experiences for students' development.

In addition, the current study measured the level of appreciation of the values for unity among multi-ethnic groups. Findings showed a high level of appreciation with a mean score of 4.29. Item "I often speak Malay language while interacting with friends from other ethnic groups" is 4.41, while the item "I always partner with a friend of other ethnic groups in a program at the campus" scored the lowest mean at 4.19 (Table 4).

These findings revealed that multi-ethnic pre-service teachers are exposed to the diversity in campus such as inter-ethnics interaction has positive effects on the community, especially on racial unity (Gurin et al., 2002). In fact, when a close pattern of social interaction is formed between the ethnic groups, it will strengthen unity and understanding of the people in this country. Therefore, this study shows that unity appreciation among students is high and this is a good thing since they are the ones who will be the agents of socialization when they are in school later.

These future teachers are able to cultivate the seeds of unity among students at schools because it is already embedded in themselves of the values of unity when they are in the institutes. In fact, when unity is strongly

Table 3. Overall summary on the level of tendency for interaction among multi-ethnic preservice teachers in the campus environment.

\begin{tabular}{rcc} 
Environment & Mean & Interpretation of Level \\
\hline Curricular environment & 4.27 & High \\
Co-curricular environment & 4.47 & High \\
Environment at residential colleges & 4.30 & High \\
Environment of daily activities & 4.35 & High \\
Websites environment & 4.17 & High \\
Overall campus environment & 4.32 & High \\
\hline
\end{tabular}

Table 4. Summary of the overall value of unity appreciation among multi-ethnic pre-service teachers.

\begin{tabular}{cc}
\hline Statement/Item & Mean \\
\hline I am proud of the excellent results achieved by students from other ethnic groups & 4.28 \\
I always use Malay language when I interact with friends of other ethnic groups & 4.41 \\
I can accept the lifestyle practiced by my friends of other ethnic groups & 4.26 \\
I always cooperate with friends of other ethnic groups when taking part in any programs & 4.19 \\
organized by the campus & 4.33 \\
O do not have any prejudice towards friends of other ethnic groups & $\mathbf{4 . 2 9}$ \\
\hline
\end{tabular}


formed, it will guarantee stability and the country will move smoothly towards progress and the nation will move towards high achievement (Aziz, Hassan, Harun, \& Yasin, 2009). This is because education helps in disseminating and sharing of values and aspirations when individuals from different socio-economic backgrounds, religions and ethnicities interact, understand and accept their differences. Shared values and experience will further strengthen unity and form a national identity.

\subsection{Relationship of Early Socialization Factors with the Tendency for Interaction among Multi-Ethnic Pre-Service Teachers}

Figure 1 shows the relationship between the effects of early socialization with pre-service teachers' tendency to interact and their appreciation of the values for unity.

Table 5 shows the coefficients path of the sub construct contribution on the influence of family, school, peer pressure and mass media in influencing the tendency to interact and to appreciate the values for unity among multi-ethnic pre-service teachers.

Based on Table 5, it shows that peer influence has the strongest influence and related with the tendency to interact. This is followed by school socialization, family, and the last one is the influence by mass media. Meanwhile, the tendency to interact does not have any influence on the appreciation of the unity value.

This means that early socialization has certain impact on the tendency for multi-ethnic pre-service teachers to interact with other multi-ethnic groups. If the effect of early socialization is strong, the influence on the tendency will relatively high. Continuous exposure by early socialization agents such as family, school, peers and the mass media about the importance of interaction with individuals from different ethnics will influence the students' perception and behavior towards other students from different ethnic groups in the institutes.

The results showed that peer has a strong influence on the tendency to interact among pre-service teachers of various ethnic groups and followed by other influences from the school, family and mass media. In fact, the impact of peer influence is also expected to foster racial unity. Peers are very influential in terms of disseminating values, attitudes and outlook on life. In fact, friends are the most influential in the socialization process because they spend much of their time with their friends in and outside the school. Findings of the study also showed that pre-service teachers' participation in sports and recreational activities would also foster racial unity.

These findings are also consistent with previous studies on socialization agents especially the family and school that can influence pre-service teachers' perceptions towards other ethnic groups (Chang, 1999). A study found that most parents encouraged their children to interact with other people, however there is a big difference of influence between parents who did not go to school with those parents who are highly educated. Family is obviously the first and most important socialization agent for children, before the children are influenced by other socialization agents. Juang \& Moin (2010) also recognized the role of family in providing a platform for the formation of ethnic identity through ethnic socialization process. Family socialization practices have contributed to the formation of ethnic identity during childhood and adolescence.

There is no doubt that teachers and schools are also able to instill a sense of tolerance, and mutual respect among students from various ethnic identities and this greatly influenced the students when they are in higher learning institutes. According to Cushner (2008), education tries to develop cross-cultural understanding, and

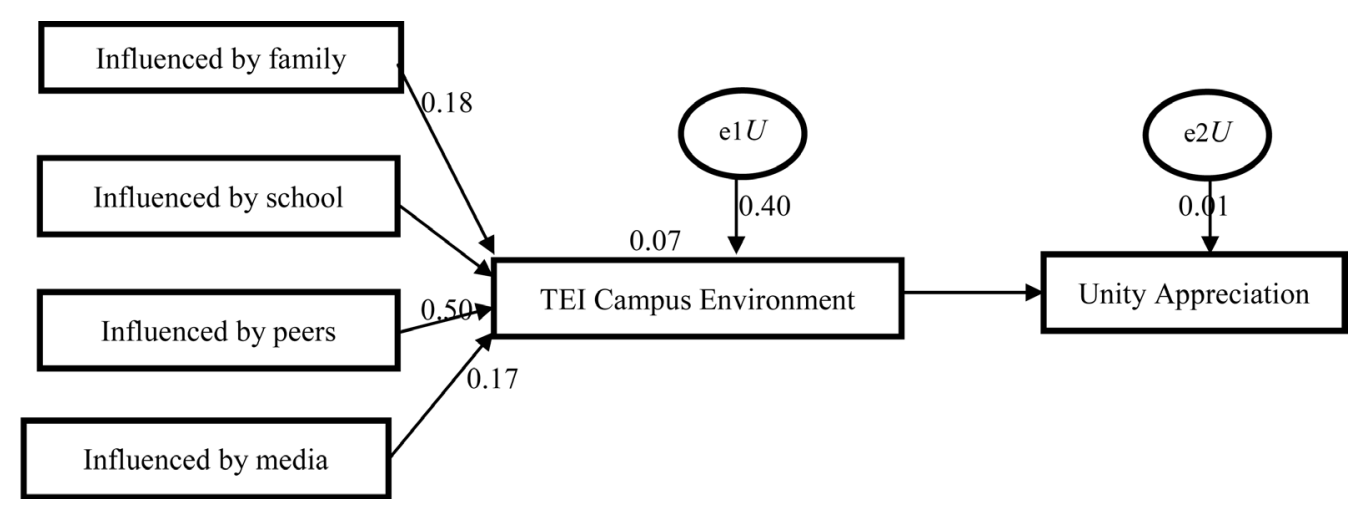

Figure 1. Structural equation modeling on the effects of early socialization. 
Table 5. The coefficients path between variables.

\begin{tabular}{rccccc}
\hline & \multicolumn{2}{c}{ Relations of Variables } & Beta & P & coefficients \\
\hline Environment & $<---$ & influenced by family & 0.183 & $* * *$ & 3.407 \\
Environment & $<---$ & influenced by school & 0.288 & $* * *$ & 5.441 \\
Environment & $<---$ & influenced by peers & 0.504 & $* * *$ & 8.712 \\
Environment & $<---$ & influenced by media & 0.173 & 0.001 & 3.283 \\
Unity appreciation & $<---$ & Environment & 0.073 & 0.134 & 1.498 \\
\hline
\end{tabular}

teach students to solve problems between cultures. Therefore, teachers can influence students' perspectives regarding various cultures and races. Similarly, a study conducted by Quintelier (2007) found that school can be successful in promoting tolerance among students from various ethnic groups by providing information on politics and cultures.

However, these findings differ with the findings of a study carried out by Noor, Aziz, \& Lee (2006) on integration among university students. The study found that most students have a high sentiment of racism. Students are more sociable with their own kind. All this happened due to the early socialization process experienced before they come to the university. Similarly, the students learnt about polarization as part of their campus life and this is likely due to the influence of habit before they enter the institution.

\section{Implications and Recommendations}

This study provides significant implications for the stakeholders, particularly the authorities of the institute. The authorities need to level up students' interaction and maintain great cohesion among students from various backgrounds. This means that, the administrators should provide support and organize activities that can foster students' interaction and cohesion. Apart from that, the management should emphasize on the quantity and quality of interaction between students from various ethnic backgrounds.

Therefore, the room-sharing basis with students from different backgrounds should be maintained. This practice is very encouraging and promising, as this enhances inter-ethnics interaction and strengthens national unity.

Similarly, great efforts to create a conducive environment should be enhanced to provide ample opportunities for students from diverse ethnic groups to interact easily and effectively. Conducive surrounding at the study areas, lounges, cafeteria, and other campus's facilities would provide ample spaces and opportunities for all students to interact with each other.

The results also show the powerful effects of peers in influencing students to interact with fellow friends of various backgrounds. Therefore, this aspect should be emphasized in the community so that they can contribute to the ongoing interaction among students and youth of various ethnicities. This in the long run will form closer and friendly relations in the plural society. Accordingly, the youth associations should enhance their efforts and activities particularly by organizing or conducting activities that may attract all kind of people to join in. Indirectly, this informal association between various ethnicities will lead to mutual understanding, honest interaction and cohesion.

In fact, effective peer group courses should also be done by the youth organizations so that the younger generation would be exposed to the knowledge especially information on ethnic diversity. This will reduce racial stereotypes and prejudice against other ethnic groups.

Regional youth visits and exchange programs among young people from the peninsula, Sabah and Sarawak and Labuan should also be considered to provide opportunities for mutual understanding, information and experience about culture diversity, values, norms and beliefs of other ethnic groups in the country. This will encourage them to be more comfortable being with others of different ethnicities without doubt and suspicion. This interaction and solidarity can develop harmony in the society.

In addition, various relevant courses on cultural diversity and ethnic relations should be conducted for the community leaders such as the tribal chiefs, village heads, and native leaders should arm themselves with knowledge of cultural diversity to overcome racial problems, upholding firmly to the ideas of freedom, justice, equality and human values. 
The results also show the role of the school as a major predictor for the pattern of interaction in the institutes. This finding is consistent with many studies about how the school is able to encourage interaction and create unity. In addition to this, the Ministry of Education has introduced Native Language (Chinese, Tamil, Iban and Kadazandusun) as a new subject in mainstream schools. This step is very appealing to attract parents to send their children to mainstream schools. This will provide opportunities for students to mix and interact with friends from various ethnic groups and of course to promote cooperation among them.

In fact, it is time to set up parent support groups in schools in collaboration with the Parent Teacher Association and the National Parent Teacher Association at the school. Through parent support groups, schools will be assisted in organizing activities outside the classrooms. Indirectly, students will gain meaningful experience that will embrace diversity and be useful in the future. They will have no problem to adapt with various kinds of people from various kinds of ethnicities because they are exposed to this experience through activities organized by the parents support groups.

\section{References}

Ahmad, A. R., Saleha, A., Jelas, Z. M., \& Seman, A. A. (2010). (Students’ Diversity and School: A Case Study in Pahang) Kepelbagaian pelajar dan sekolah: Satu kajian kes di Negeri Pahang. Jurnal Pendidikan Malaysia, 35, 87-95.

Aziz, Z., Hassan, A., Harun, H., \& Yasin, M. Z. (2009). (Improving Ethnic Relations among Students) Meningkatkan aktiviti perpaduan dalam kalangan pelajar. Research Report, Selangor Malaysia—Faculty of Education UKM.

Baharuddin, S. A. (2007). (Ethnic Relation Module) Modul Hubungan Etnik. Shah Alam: Pusat Penerbitan Universiti, Universiti Teknologi MARA.

Bronfenbrenner, U. (2005). Making Human Beings Human: Bioecological Perspectives on Human Development. Thousand Oaks, CA: Sage Publications.

Chang, M. J. (1999). Does Racial Diversity Matter? The Educational Impact of Racially Diverse Undergraduate Population. Journal of College Student Development, 40, 377-379.

Chang, M. J., Astin, A. W., \& Kim, D. (2004). Cross-Racial Interaction among Undergraduates: Some Consequences, Causes and Patterns. Research in Higher Education, 45, 529-553. http://dx.doi.org/10.1023/B:RIHE.0000032327.45961.33

Cushner, K. (2008). International Socialization of Young People; Obstacles and Opportunities. International Journal of Intercultural Relations, 32, 164-173. http://dx.doi.org/10.1016/j.ijintrel.2007.09.004

Dawi, A. H. (2004). (Ethnic relation in HEI: Ethnographic Studies among Multi-Ethnic Students). Hubungan Etnik di IPT: Satu Kajian Etnografi Habitus dan Modal Budaya di Kalangan Pelajar Berlainan Etnik. Unpublished PhD Thesis, Faculty of Education, UKM Bangi Selangor Malaysia.

Dawi, A. H. (2006). (Sociological and Educational Theories) Penteorian Sosiologi dan Pendidikan. Edisiketiga, Tanjong Malim Malaysia: Quantom Books.

Gurin, P., Dey Eric, L., Hurtado, S., \& Gurin, G. (2002). Diversity and Higher Education: Theory and Impact Educational Outcomes. Harvard Educational Review, 72, 1-26. http://dx.doi.org/10.17763/haer.72.3.01151786u134n051

Juang, L., \& Moin, S. (2010). Family Cultural Socialization Practice and Ethnic Identity in College-Going Emerging Adults. Journal of Adolescence, 33, 347-354. http://dx.doi.org/10.1016/j.adolescence.2009.11.008

Karim, F., \& Meerah, T. (1986). (Outside Classroom Interaction Pattern) Pola interaksi kaum remaja di luar bilik darjah: Satu tinjauan. Paper Works Presented in the National Education Conference, Malaysian Education Association, 15-17 November 1986, 33-40.

Khairi, A. (2011). (1 Malaysia Concept) Konsep Malaysia dan cabaran pelaksanaannya kearah pemanta panper paduan sebuah Negara-bangsa. Sosiohumanika, 4, 129-140.

Kim, Y. K., \& Sax, L. J. (2007). Different Patterns of Student-Faculty Interaction in Research Universities: An Analysis by Student Gender, Race, SES, and First-Generation Status. Research Occasional Paper Series, University of California: Center of Studies Higher Education.

Mustapha, R., Azman, N., Karim, F., Ahmad, A. R., \& Lubis, M. A. (2009). A Survey of Social Interaction among Diverse Students in Malaysian Higher Learning Institutions. International Journal of Learner Diversity, 1, 93-112.

Noor, M. M., Aziz, A. A. R. \& Lee, I. M. A. (2006). (Ethnic Relations in Malaysia) HubunganEtnik di Malaysia. Petaling Jaya: Prentice Hall.

Peng, C. P. (2007). (Malay Arts and Ethnicity: Issues and Challenges) Sastera Melayu dan prasangka etnik: Isu-isu dan persoa-lan. Masalah Pendidikan, 30, 61-78.

Quintelier, E. (2007). European Citizenship and Ethnic Tolerance among Adolescent: Result of a Representative Survey 
among Belgian 16 Years Old. Kertas Kerja Persidangan European Sociological Association: Youth Globalization and Migration Local Diversity in Transition, Smolenice, Slovania, 19-22 Januari.

Ramli, A. H. (2009). (Ethnic Relation in Malaysia) Hubungan Kaum di Malaysia. Shah Alam: Pusat Penerbitan Universiti.

Rodrigues-Garcia, J. M., \& Wagner, U. (2009). Learning to Be Prejudiced: A Test on Unidirectional and Bidirectional Models of Parents-Offspring Socialization. International Journal of Intercultural Relation, 33, 516-523. http://dx.doi.org/10.1016/j.ijintrel.2009.08.001

Seltzer, V., \& Waterman, R. (1996). A Cross National Study of Adolescent over Concordance on Issue of the Future. Journal of Adolescent Research, 88, 461-482. http://dx.doi.org/10.1177/0743554896114005

Tamam, E. (2009). Contribution of Interethnic Contact on Interethnic Attitudes of Malay and Chinese-Malaysian University Students in Malaysia. European Journal of Social Sciences, 8, 51-61.

Umbach, P. D., \& Kuh, G. D. (2006). Student Experiences with Diversity at Liberal Arts College: Another Claim for Distinctiveness. The Journal of Higher Education, 77, 169-192. http://dx.doi.org/10.1353/jhe.2006.0008

Zainal, K., Abu, T., \& Mohamad, Z. (2010). The Effect of Ethnic Relation Course on the Student's Perception towards Ethnic Relations among First Year Student of One Public University in Malaysia. Pocedia Social and Behavioral Science, 2, 3596-3599. http://dx.doi.org/10.1016/j.sbspro.2010.03.558 